This item was submitted to Loughborough's Research Repository by the author.

Items in Figshare are protected by copyright, with all rights reserved, unless otherwise indicated.

\title{
The use of bond graph modelling in polymer electrolyte membrane fuel cell fault diagnosis
}

\section{PLEASE CITE THE PUBLISHED VERSION}

https://doi.org/10.1201/9781351174664

\section{PUBLISHER}

(C) Taylor and Francis

\section{VERSION}

VoR (Version of Record)

\section{PUBLISHER STATEMENT}

This work is made available according to the conditions of the Creative Commons Attribution-NonCommercialNoDerivatives 4.0 International (CC BY-NC-ND 4.0) licence. Full details of this licence are available at: https://creativecommons.org/licenses/by-nc-nd/4.0/

\section{LICENCE}

CC BY-NC-ND 4.0

\section{REPOSITORY RECORD}

Vasilyev, Andrey, John Andrews, Lei Mao, and Lisa M. Jackson. 2019. "The Use of Bond Graph Modelling in Polymer Electrolyte Membrane Fuel Cell Fault Diagnosis”. figshare. https://hdl.handle.net/2134/37273. 


\title{
The use of bond graph modelling in polymer electrolyte membrane fuel cell fault diagnosis
}

\author{
A. Vasilyev \& J. Andrews \\ Department of Mechanical, Electrical and Manufacturing Engineering, Loughborough University, UK \\ L. Mao \& L.M. Jackson \\ Department of Aeronautical and Automotive Engineering, Loughborough University, UK
}

\begin{abstract}
As a possible alternative energy source, hydrogen fuel cells, especially Polymer Electrolyte Membrane (PEM) fuel cells, have received much more attention in the last few decades, which have already been equipped in many applications. A series of studies have been devoted to PEM fuel cell fault diagnosis to ensure its reliability during its lifetime, but due to the complexity of PEM fuel cell systems and incomplete PEM fuel cell test protocols, it is difficult to test various PEM fuel cell failure modes, thus the performance of fault diagnostic techniques cannot be fully investigated. On this basis, it is necessary to develop a reliable PEM fuel cell model with capability of simulating various PEM fuel cell faults. In this study, a hybrid model is developed to represent the behavior of PEM fuel cells in both continuous and discrete-time domains. With a continuous-time domain sub-model, various aspects of PEM fuel cell behavior can be simulated, including fluid, thermal, and electro-chemical dynamics. Moreover, the PEM fuel cell failure modes are implemented with stochastic Petri nets in the discrete-time domain. Based on the developed hybrid model, various PEM fuel cell failure modes can be simulated and their effects on the system performance can be observed. With the simulated data under different conditions, the performance of fault diagnostic techniques can be better evaluated by studying their performance in different failure mode scenarios.
\end{abstract}

\section{INTRODUCTION}

Due to the characteristics such as zero-emission and high efficiency, the PEM fuel cell has attracted more attention as an alternative energy source. In the last few decades, PEM fuel cells have been equipped in several systems, including automotive, consumer devices, and stationary power systems.

However, the reliability of PEM fuel cell during its lifetime is still a main barrier for further commercialization. To address this, several studies have been devoted to PEM fuel cell fault diagnosis, which could detect and isolate PEM fuel cell abnormal performance, thus mitigation strategies can be taken to recover and extend the fuel cell performance. Based on the methods adopted, these studies can be loosely divided into two categories, modelbased techniques and data-driven approaches [Petrone et al. 2013, Zheng et al. 2013].

In model-based techniques, a PEM fuel cell model should be developed to express the system behavior, and the fault can be identified by calculating the residual between the model outputs and actual measurements [Kamal and Yu 2011, Ohs et al. 2011, Zeller et al. 2010]. With data-driven approaches, the features indicating the fuel cell con- dition would be extracted from the measurements, and the fuel cell state can be determined by applying pattern recognition algorithms to the extracted features [Mao et al. 2017, Placca et al. 2010, Rubio et al. 2010, Steiner et al. 2011, Zhongliang et al. 2015].

From the previous studies, data-driven approaches are more widely used in PEM fuel cell fault diagnosis [Zheng et al. 2013]. The main reason is that the PEM fuel cell contains physical interactions consisting phenomena from fluidic, thermal and electrical domains, making it difficult to develop an accurate model, where data-driven approach can perform fault diagnosis using only measurements from PEM fuel cell system.

However, due to the incomplete protocol of the PEM fuel cell failure tests, only limited PEM fuel cell failure mode conditions can be tested in the lab, [Yuan et al. 2011, Miller and Bazylak 2011], which cannot fully investigate the effectiveness of data-based fault diagnostic techniques. Therefore, further studies for the performance of these approaches indiagnosing more PEM fuel cell failure modes are still required.

In this study, a PEM fuel cell model is developed based on the bond graph technique, which 
can represent multiple physical phenomena in a unified graphical notation. With the developed model, various PEM fuel cell failure modes can be simulated, and simulated data can be used in data-based fault diagnostic techniques to investigate their effectiveness. In section 2, the knowledge of the PEM fuel cell and development of its bond graph model will be presented. The performance of the developed model in representing PEM fuel cell performance will be validated in section 3 . In section 4 , the model will be used to simulate the fuel cell dehydration phenomenon, and the performance of data-based fault diagnostic techniques will be studied using the simulated data. From the results, some conclusions are given in section 5 .

\section{PEM FUEL CELL BOND GRAPH MODEL}

\subsection{Introduction of PEM fuel cell}

A typical PEM fuel cell includes several components, i.e. anode and cathode electrodes, gas diffusion layer, catalyst layer, and polymer electrolyte membrane, which are depicted in Figure 1.

During operation, hydrogen and air/oxygen are injected into the anode and cathode sides, respectively. Hydrogen is divided into protons and ions with Eq. (1), protons can pass through the membrane, while ions can only arrive at the cathode via the external circuit, where current is generated. At the cathode side, protons, ions, and oxygen will react to produce heat and water (Eq. 2), which can be removed from the cathode side.

$$
\begin{aligned}
& \mathrm{H}_{2} \rightarrow 2 \mathrm{H}^{+}+2 \mathrm{e}^{-} \\
& \frac{1}{2} \mathrm{O}_{2}+2 \mathrm{H}^{+}+2 \mathrm{e}^{-} \rightarrow \mathrm{H}_{2} \mathrm{O}
\end{aligned}
$$

\subsection{Bond Graph method}

The core principle of the bond graph (BG) method is energy conservation, i.e. the total energy in a

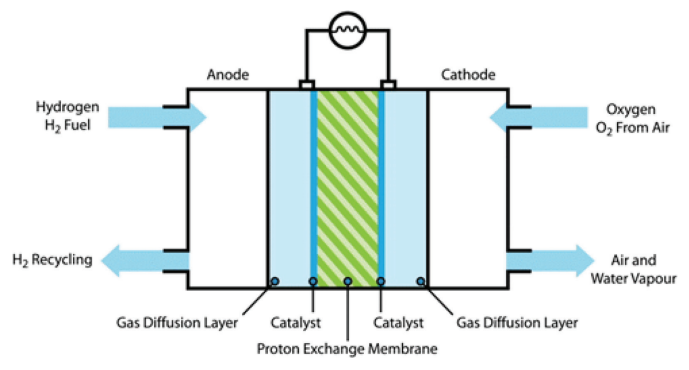

Figure 1. A typical PEM fuel cell. closed system is never destroyed or lost, but converted from one form to another. With this method, systems involving multiple physical domains can be unified.

In a $\mathrm{BG}$ the rate at which energy is transferred between components is power, which is denoted as a half arrow as shown in Figure 2. It can be seen that power flow is characterized by two power variables: effort (e) and flow (f), where

$$
\mathrm{e} \times \mathrm{f}=\text { power }
$$

Table 1 depicts some commonly used analogies for the meanings of effort and flow.

Elements in the BG are located at the BG nodes, and represent different energy manipulation mechanisms. Sources of effort (Se) and flow (Sf) are active elements and provide inputs to the system. Such elements, controlled by an external signal, are called 'modulated' and denoted by a prefix ' $m$ ', e.g. $\mathrm{mSe}$. Energy dissipation and storage phenomena are implemented via resistive $(\mathrm{R})$, capacitive $(\mathrm{C})$ or inductive (I) elements. Detectors of effort (De) and flow (Df) are shown with a full arrow to emphasize that they do not participate in energy exchange, but rather simply act as sensors and measure corresponding power variables.

Multiple power bonds can meet at one of two junction types, 0 - and 1-type, which enforce the laws of energy conservation within the system. Another junction structure called Transformers (TF) act as energy transducers converting the transferred power from one physical domain to another. TF elements can only have two bonds connected. Figure 3 shows the different junction types, and corresponding equations are written in Eqs. (4)-(6).

1-junction $f_{1}=f_{2}=\ldots=f_{N} \sum e_{N}=0$

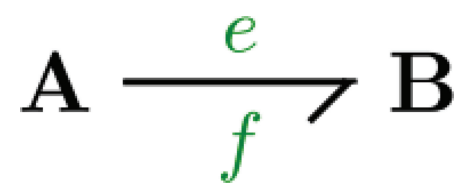

Figure 2. Power bond between objects A and B.

Table 1. Physical analogies for power variables.

\begin{tabular}{lll}
\hline Domain & Effort & Flow \\
\hline Electrical & Voltage & Current \\
Mechanical & Force & Velocity \\
Pneumatic & Pressure & Volumetric flow \\
Chemical & Chemical potential & Molar flow \\
Thermal & Temperature & Entropy flow \\
\hline
\end{tabular}


0-junction $e_{1}=e_{2}=\ldots=e_{N} \sum f_{N}=0$

Transformer $e_{1}=m e_{2} f_{2}=m f_{1}$

\subsection{EM fuel cell $B G$}

The hierarchy of the PEM fuel cell BG includes basic bond graphic elements describing energy storage and transfer mechanisms, which are at the base. A set of BG elements describing pneumatic and heat transfer phenomena are constructed for the two bipolar plates and for the anode and cathode sides, and BG elements describing electrochemical, transport and thermal phenomena representing the membrane electrode assembly [Saisset et al. 2006]. Additionally, cooling channels and the end plates are implemented as separate components [Vasilyev et al. 2017].

Figure 4 depicts the blocks resembling physical components of the PEM fuel cell and bonds connecting them representing power flows between components. Anode/cathode inlet and outlet blocks correspond to mass flow controllers or

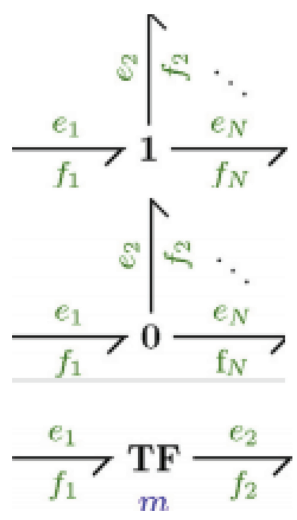

1 -junction

0-junction

transformer

Figure 3. Bond graph junctions.

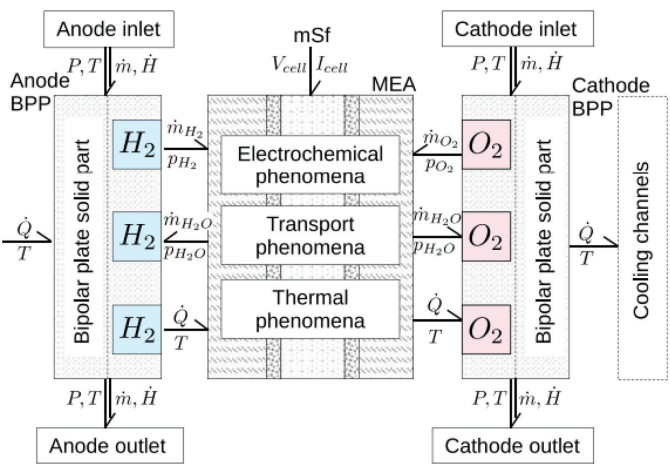

Figure 4. PEM fuel cell BG [Vasilyev et al. 2017]. valves and regulate the flow of matter in or out of the cell. This is shown by bond labelled with $\mathrm{P}, \mathrm{T}$ as efforts and $\dot{m}, \dot{H}$ as flows. The source of electric current $(\mathrm{mSf})$ represents the load demanded from the fuel cell. Electrochemical phenomena within the membrane electrode assembly components calculate the rates of reactants and product consumption $\dot{m}_{\mathrm{H}_{2}}, m_{\mathrm{O}_{2}}$ and $\dot{m}_{\mathrm{H}_{2}}$. Transport phenomena determine the diffusion flows through the membrane electrode assembly, while thermal effects evaluate heat flows $\dot{Q}$ between the bipolar plates and the membrane.

A set of equations are used to develop the PEM fuel cell $\mathrm{BG}$, including the computation of mass flow rates of gasses in and out of the cell, and thermal and pneumatic activities within bipolar plates. More details about the modelling procedures for the PEM fuel cell BG can be found in previous studies [Gawthrop and Bevan 2007, Vasilyev et al. 2017].

With results from different PEM fuel cell components, the single cell voltage can be calculated using Eq. (7).

$$
V_{\text {cell }}=E_{\text {Nernst }}-\eta_{\text {act }}-\eta_{\text {ohm }}-\eta_{\text {con }}
$$

where $E_{\text {Nernst }}$ is the reversible potential, $\eta_{\text {act }}, \eta_{\text {ohm }}$ and $\eta_{c o n}$ are the activation loss, ohmic loss, and concentration loss, respectively.

Figure 5 depicts the single PEM fuel cell BG by putting the developed individual components together. Figure 6 shows the PEM fuel cell system BG including single cell BG and cooling loops, where inlet mass flows are regulated by Rth 1 and Rth2. Each cooling loop is comprised of a single

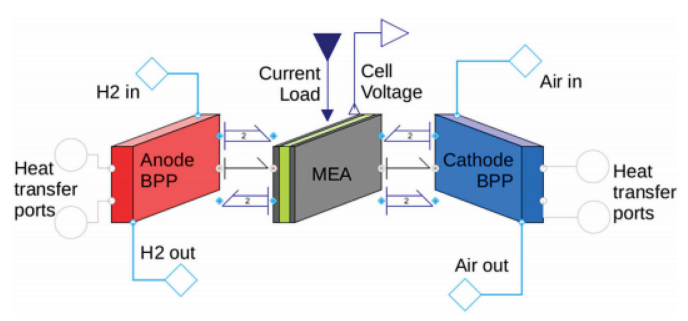

Figure 5. Single PEM fuel cell BG [Vasilyev et al. 2017].

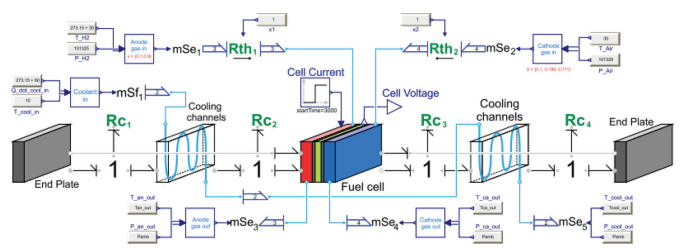

Figure 6. PEM fuel cell system BG [Vasilyev et al. 2017]. 
Cth-element and elements RC1-4 calculating the heat transfer rate.

\section{VALIDATION OF PEM FUEL CELL BG}

Before using the developed PEM fuel cell BG in fault diagnosis, the performance of the developed $\mathrm{BG}$ should be validated.

In this study, the Electrochemical Impedance Spectroscopy (EIS) is obtained from the test to determine the model parameters including electrical resistance and double layer capacitance. With the determined model parameters, the polarization cure is obtained from the model and compared with those from the test, the comparison results are depicted in Figure 7.

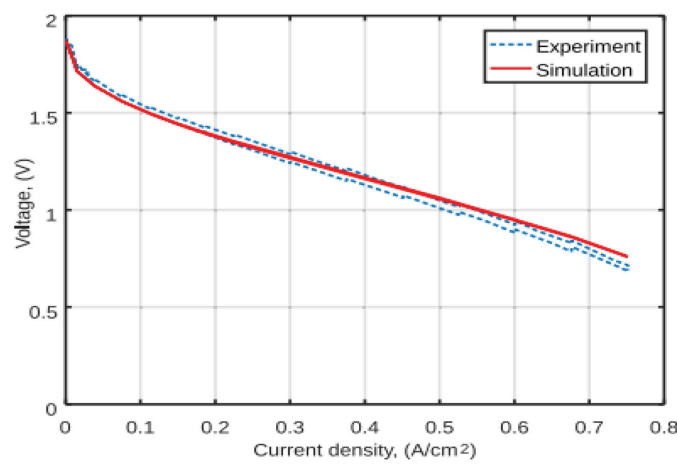

Figure 7. Comparison results of polarization curves between the model and test [Vasilyev et al. 2017].
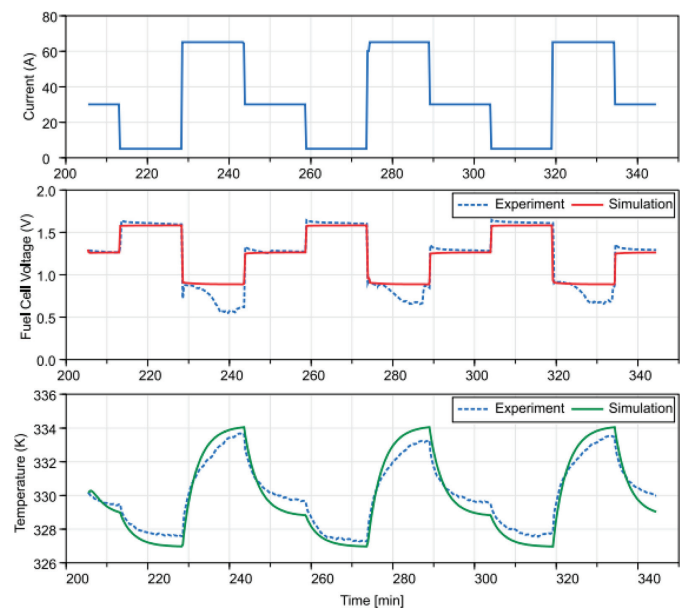

Figure 8. Comparison results of cell voltage and temperature curves between the model and test [Vasilyev et al. 2017].
It can be seen from Figure 7 that the overall polarization from the model can match the tested data with good accuracy, and the deviation becomes slightly larger in the region of concentration loss with current density higher than 0.55 $\mathrm{A} / \mathrm{cm}^{2}$. The reason is that the model doesn't fully consider the electrode porosity and effects of liquid water formation within the cell.

Furthermore, a test with varying current densities is performed, and the cell voltage and temperature are obtained and compared with those from the developed model. Results are shown in Figure 8. It can be seen that the developed model can capture the PEM fuel cell behavior with good quality, which paves the way for using the developed model for the following analysis.

\section{USE OF FUEL CELL BG MODEL FOR FAULT DIAGNOSIS}

\subsection{Simultion of PEM fuel cell failure mode}

In this study, dehydration is simulated and the simulated data is used to test the performance of datadriven fault diagnostic approaches. The reason for selecting dehydration is that it is a commonly experienced failure mode in PEM fuel cell systems due to unbalanced water management. Moreover, dehydration is not usually performed in testing as it will cause permanent damage of the membrane. Therefore, with the developed PEM fuel cell BG model, the performance of data-driven approaches can be investigated more efficiently in terms of both computational time and financial cost.

In the simulation, the constant current $(70 \mathrm{~A}$ herein) is applied to the developed model, and after normal operation of a certain time, the relative humidity at the anode side is reduced from $100 \%$ to $50 \%$ at $500 \mathrm{~h}$, which can cause decreased water contents within the cell and thus dehydration. Figure 9 depicts the variation of anode relative humidity, voltage, and stack temperature.

It can be seen from Figure 9 that when operated at the constant condition, PEM fuel cell voltage will decay linearly, representing the degradation phenomena due to fuel cell aging. Moreover, with decrease of anode relative humidity, stack voltage shows a more steep decrease, and the increased stack temperature can be observed more clearly, this is due to the reduced water content within the cell from the reduced relative humidity of inlet gas.

\subsection{Data-driven fault diagnostic approaches}

In this study, several fault diagnostic approaches have been applied to the simulated data for both normal and dehydration conditions. As data from 

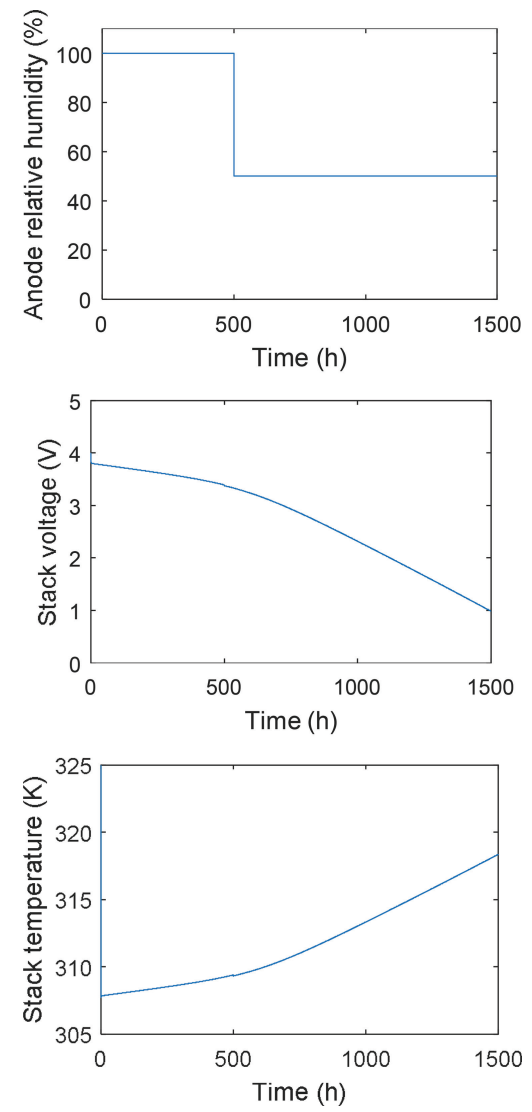

Figure 9. Simulation results of anode relative humidity, fuel cell stack voltage, and stack temperature.

multiple sensors are simulated, the approaches reducing the size of dataset is applied, Kernel Principal Component Analysis (KPCA) is selected herein due to its better performance in non-linear systems. After that, wavelet packet transform (WPT) is applied to decompose the original signal into different frequency ranges, from which the features are constructed. The features with the highest values are used in this case to discriminate the PEM fuel cell states. This flowchart is illustrated in Figure 10. It should be noted that the selected diagnostic framework is effective in identifying various failure modes in PEM fuel cell systems [Mao et al. 2017]. More details about these approaches can be found in previous studies [Mao et al. 2017, Placca et al. 2010].

\subsection{Diagnostic results}

In the analysis, simulation data from multiple sensors are used, which are listed in Table 2. The
Reduction of dataset dimension using KPCA

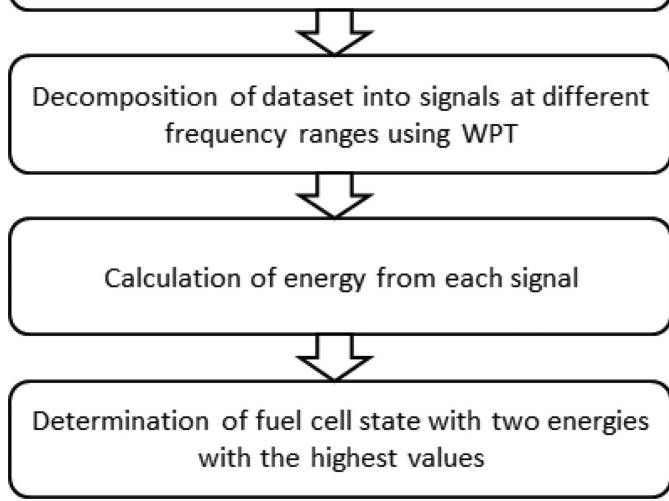

Figure 10. Flowchart of PEM fuel cell fault diagnosis using data-driven approaches.

Table 2. Sensor measurements used in the analysis.

\begin{tabular}{llll}
\hline Sensor & Unit & Sensor & Unit \\
\hline Voltage & $V$ & Air inlet flow & l/min \\
H2 inlet flow & l/min & Air inlet pressure & bar \\
H2 inlet pressure & bar & Air outlet pressure & bar \\
H2 outlet pressure & bar & Air inlet temperature & $K$ \\
H2 inlet temp & $K$ & Stack temperature & $K$ \\
\hline
\end{tabular}

reason of using multiple sensors is that multiple sensors can provide complementary information about the PEM fuel cell performance, which should be included in order not to lose useful information, without further interpretation of the sensor measurements.

KPCA is applied to the dataset including measurements from sensors (listed in Table 2) to project the dataset into the two principal directions. It should be noted that the simulated data shown in Figure 9 is divided into 2 parts representing different states (normal and dehydration), and each part is further divided into several segments for the following analysis.

WPT is then applied to each segment data from KPCA over 3 levels, the extracted wavelet coefficients are used to re-construct the signals at different frequency ranges, from which the signal energies are calculated. Figure 11 depicts the energy distribution at both normal and dehydration states.

It can be seen from Figure 11 that the energy shows similar distribution at different PEM fuel cell states, and the first few highest energies are 


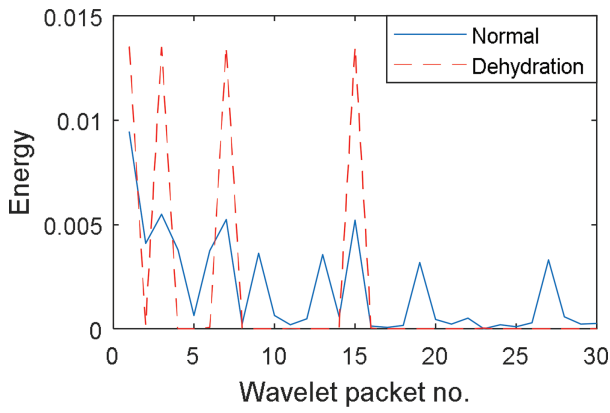

Figure 11. Distribution of energy from signals at different frequency ranges.

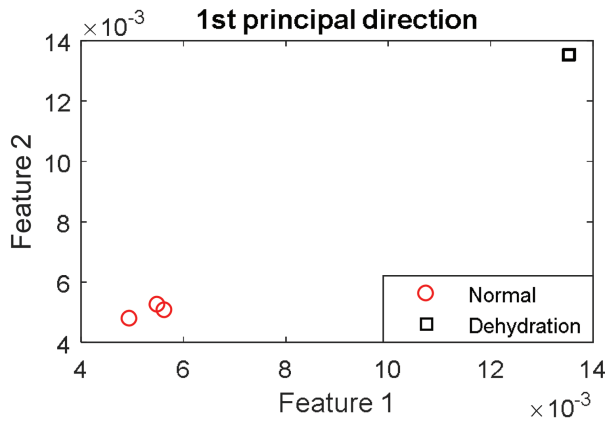

(a) Discrimination results at 1 st principal direction

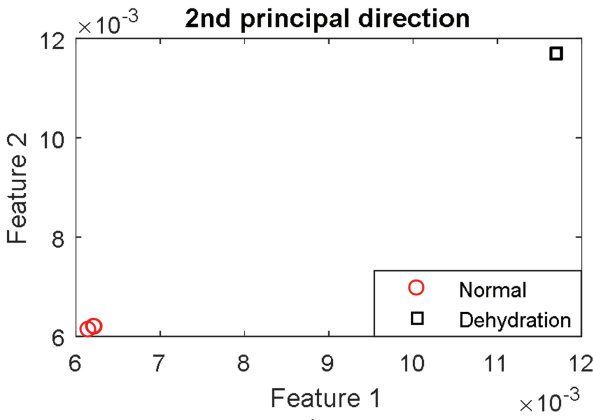

(b) Discrimination results at $2^{\text {nd }}$ principal direction

Figure 12. Discrimination results using selected features.

located at the same wavelet packet. Therefore, the first two highest energies are used as features herein for the discrimination. The results are shown in Figure 12. Since KPCA is used to project the original dataset into the two principal directions, the discrimination results at these two directions are depicted. It can be observed that the dehydration state can be discriminated with good quality from the normal state, indicating the applied data-driven approaches can identify the PEM fuel cell dehydration accurately.

\section{CONCLUSIONS}

In this paper, the PEM fuel cell model is developed using the bond graph technique, which can represent the various behaviours in PEM fuel cell system. The model parameters are determined using the collected EIS from the PEM fuel cell, and the performance of developed model is validated using the fuel cell test data at different conditions.

With the developed PEM fuel cell bond graph model, the data from different fuel cell failure scenarios can be simulated. In this study the fuel cell dehydration is simulated, and the simulated data is used in the data-driven fault diagnostic approaches. Results demonstrate that the used approaches can discriminate the dehydration state with good quality. In the future study, more fuel cell failure modes will be simulated using the developed model, and the capability of various fault diagnostic approaches in identifying these fuel cell faults can be fully investigated.

\section{ACKNOWLEDGEMENT}

The work is supported by grant EP/K02101X/1 for Loughborough University from the UK Engineering and Physical Sciences Research Council (EPSRC). The authors also acknowledge the industrial and academic collaborators of the RESILIENCE project (Robust Lifecycle Design and Health Monitoring for Fuel Cell Extended Performance).

\section{REFERENCES}

Gawthrop, P., Bevan, G. 2007. Bond-graph modelling, IEEE Control Systems Magazine 27(2):24-45.

Kamal, M.M., Yu, D. 2011. Model based fault detection for proton exchange membrane fuel cell systems, International Journal of Engineering, Science and Technology 3(9): 1-15.

Mao, L., Jackson, L.M., Dunnett, S.J. 2017. Fault diagnosis of practical polymer electrolyte membrane (PEM) fuel cell system with data-driven approaches, Fuel Cells 17(2):247-258.

Miller, M., Bazylak, A. 2011. A review of polymer electrolyte membrane fuel cell stack testing, Journal of Power Sources 196:601-613.

Petrone, R., Zheng, Z., Hissel, D., Pera, M.C., Pianese, C., Sorrentino, M., Becherif, M., Yousfi-Steiner, N. 2013. A review on model-based diagnosis methodologies for PEMFCs, International Journal of Hydrogen Energy 38(17): 7077-7091.

Placca, L., Kouta, R., Candusso, D., Blachot, J.F., Charon, W. 2010. Analysis of PEM fuel cell experimental data using principal component analysis and multi linear regression, International Journal of Hydrogen Energy 35(10):4582-4591.

Ohs, J.H., Sauter, U., Maass, S., Stolten, D. 2011. Modelling hydrogen starvation conditions in pro- 
ton exchange membrane fuel cells, Journal of Power Sources 196(1):255-263.

Rubio, M.A., Urquia, A., Dormido, S. 2010. Diagnosis of performance degradation phenomenon in PEM fuel cells, International Journal of Hydrogen Energy 35(7):2586-2590.

Saisset, R., Fontes, G., Turpin, C., Astier S. 2006. Bond graph model of a PEM fuel cell, Journal of Power Sources 156(1):100-107.

Steiner, N.Y., Hissel, D., Mocoteguy, P., Candusso, D. 2011. Non intrusive diagnosis of polymer electrolyte fuel cells by wavelet packet transform, International Journal of Hydrogen Energy 36(1):740-746.

Vasilyev, A., Andrews, J., Jackson, L.M., Dunnett, S.J., Davies, B. 2017. Component-based modelling of PEM fuel cells with bond graphs, International Journal of Hydrogen Energy 42(49):29406-29421.

Yuan, X., Li, H., Zhang, S., Martin, J., Wang, H. 2011. A review of polymer electrolyte membrane fuel cell durability test protocols, Journal of Power Sources 196:9107-9116.

Zeller, A., Rallieres, O., Regnier, J., Turpin, C. 2010. Diagnosis of a hydrogen/air fuel cell by a statistical model-based method, Vehicle Power and Propulsion Conference (VPPC), Lille, France.

Zheng, Z., Petrone, R., Pera, M.C., Hissel, D., Becherif, M., Pianese, C., Steiner, N.Y., Sorrentino, M. 2013. A review on non-model based diagnosis methodologies for PEM fuel cell stacks and systems, International Journal of Hydrogen Energy 38():8914-8926.

Zhongliang, L., Outbib, R., Giurgea, S., Hissel, D., Li, Y. 2015. Fault detection and isolation for polymer electrolyte membrane fuel cell systems by analysing cell voltage generated space, Applied Energy 148:260-272. 